\section{SAT0161 PRELIMINARY REAL WORLD DATA ON SWITCHING PATTERNS BETWEEN ETANERCEPT, ITS RECENTLY MARKETED BIOSIMILAR COUNTERPART AND ITS COMPETITOR ADALIMUMAB, USING SWEDISH PRESCRIPTION REGISTRY}

R. Alten ${ }^{1}$, P. Neregård ${ }^{2}$, H. Jones ${ }^{3}$, E. Singh ${ }^{3}$, C. Curiale ${ }^{4}$, T. Meng ${ }^{5}$, L. Lucchese ${ }^{6}$, C. Miglio ${ }^{6}$, J. Young ${ }^{7}$, G.J. Bergman ${ }^{7} .{ }^{1}$ Schlosspark-Klinik, Berlin, Germany; ${ }^{2}$ Pfizer, Stockholm, Sweden; ${ }^{3}$ Pfizer, Collegeville, United States; ${ }^{4}$ Pfizer, Rome, Italy; ${ }^{5}$ Pfizer, Berlin, Germany; ${ }^{6}$ QuintilesIMS, London, United Kingdom; ${ }^{7}$ QuintilesIMS, Solna, Sweden

Background: The increasing availability of biologic treatments over the past 10 years has revolutionized the management of chronic inflammatory autoimmune diseases such as rheumatic diseases. In April 2016, the first etanercept biosimilar (EtnBS) was launched in Sweden, which may represent a cheaper option to its innovator counterpart and other anti-TNF agents.

Objectives: The objective of this study was to describe the position of etanercept innovator (Etnl) within the Swedish biologic market for rheumatic diseases, before and after the launch of its biosimilar. The study also provides early real-world data on the market penetration of EtnBS by evaluating switching dynamics to and from this drug since the date of launch.

Methods: The overall biologic market share across all type of rheumatic diseases was monthly tracked over the last year of available data in the Swedish Prescription Registry ( $100 \%$ coverage). The proportion of patients receiving a rheumatologists' prescription for any biologic in each month, from November 2015 to October 2016, was recorded. In addition, switching dynamics of patients initiating EtnBS treatment between April 2016 and October 2016 were studied. The proportion of patients receiving no biologic treatment (naïve) and of those on treatment with Etnl, adalimumab and other biologic agents in the 12 months prior to initiate EtnBS was reported. Further, the proportion of patients who switched from EtnBS back to Etnl or adalimumab and the mean time to this second switch were also evaluated.

Results: Etnl and adalimumab dominate the biologic market for rheumatic diseases in Sweden, holding the $40 \%$ and $28 \%$ of market share, respectively, up to April 2016. However, in the 6 months after EtnBS was launched, the share of Etnl decreased constantly, dropping to $31 \%$ in October 2016 (Figure 1). Since April 2016, we identified in total 2,439 patients receiving first prescription of EtnBS by a rheumatologist. Of these, $977(40.1 \%)$ were naïve to biologic, $1,179(48.3 \%)$ had prior treatment with Etnl, 107 (4.4\%) with adalimumab, 176 (7.2\%) with other biologics. Among the patients who changed to EtnBS from prior Etnl, the 7\% switched back to Etnl after an average time of 43 days. Similarly, of those who were on previous adalimumab treatment, $6 \%$ switched back to adalimumab after, on average, 57 days.

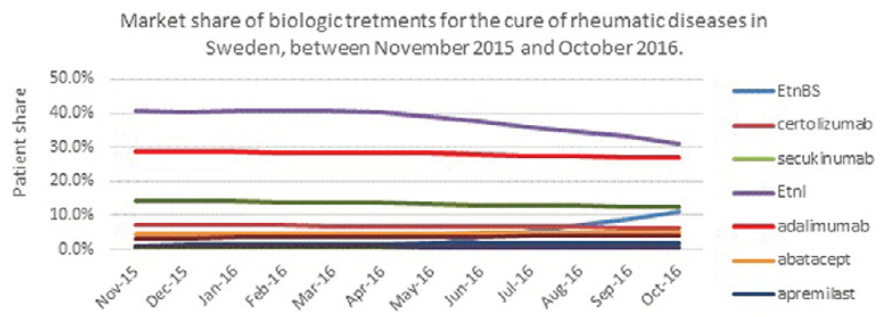

Conclusions: Many patients changed from Etnl to its biosimilar treatment since its launch in Sweden. However, this study showed that $7 \%$ of these patients switch back to their original treatment after short time. Despite the change from a brand biologic to the biosimilar is very likely made for economic reasons, the reasons for switching back to the innovator are not clear and may imply patients' preference or clinical reasons. Interestingly, the same pattern is observed for patients changing from adalimumab to EtnBS. Longer-term studies are required to confirm these early observations and investigate the reasons for switching back.

Disclosure of Interest: R. Alten Grant/research support from: The study was sponsored by Pfizer, P. Neregård Employee of: Pfizer, $\mathrm{H}$. Jones Employee of: Pfizer, E. Singh Employee of: Pfizer, C. Curiale Employee of: Pfizer, T. Meng Employee of: Pfizer, L. Lucchese Grant/research support from: The study was sponsored by Pfizer, C. Miglio Grant/research support from: The study was sponsored by Pfizer, J. Young Grant/research support from: The study was sponsored by Pfizer, G. J. Bergman Grant/research support from: The study was sponsored by Pfizer

DOI: 10.1136/annrheumdis-2017-eular.3585

\section{SAT0162 SWITCHING FROM ETANERCEPT TO CHS-0214: A ONE YEAR, RANDOMIZED, DOUBLE-BLIND STUDY IN PATIENTS WITH RHEUMATOID ARTHRITIS}

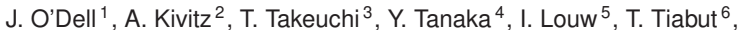
S. Nakashima ${ }^{7}$, J. Hodge $^{8}, \mathrm{H}$. Tang ${ }^{8}$, B. Finck ${ }^{8}$ on behalf of The RApsody Study Group. ${ }^{1}$ University of Nebraska Medical Center, Omaha, NE; ${ }^{2}$ Altoona Center for Clinical Research, Duncansville, PA, United States; ${ }^{3}$ Keio University School of Medicine, Tokyo; ${ }^{4}$ School of Medicine, University of Occupational and Environmental Health, Kitakyushu, Japan, ${ }^{5}$ Panorama Medical Center, Cape
Town, South Africa; ${ }^{6}$ City Clinical Hospital No. 1 of Minsk, Minsk, Belarus; ${ }^{7}$ Daiichi-Sankyo, Tokyo, Japan; ${ }^{8}$ Coherus BioSciences, Redwood City, United States

Background: CHS-0214 is in development as a proposed biosimilar of etanercept for the treatment of rheumatoid arthritis (RA) and other auto-immune diseases. Objectives: Equivalence of CHS-0214 to etanercept was demonstrated at 24 weeks in a global confirmatory, safety and efficacy study in patients with RA. This update provides efficacy results at 48 weeks and safety results over 52 weeks (or over 48 weeks for subjects who continued to the open-label safety extension study).

Methods: Patients had moderate/severe RA and an inadequate response to methotrexate (MTX). Patients were randomized to CHS-0214 or etanercept (commercial European-sourced) at $50 \mathrm{mg} \mathrm{SC} \mathrm{QW} \mathrm{for} 24$ weeks (Part 1). Patients achieving ACR20 at Week 24 with no safety concerns then received CHS-0214 $50 \mathrm{mg}$ SC QW open-label for 24 weeks (Part 2). Patients continued their stable dose of MTX throughout the study.

Results: At Week 24, the response rates were $91.0 \%$ vs. 90.6\% for ACR20, $67.6 \%$ vs. $63.7 \%$ for ACR 50 , and $38.3 \%$ vs. $37.9 \%$ for ACR70, in the CHS- 0214 group $(n=256)$ vs. etanercept group $(n=256)$, respectively. At Week 48 , the response rates were $93.8 \%$ vs. $92.7 \%$ for ACR20, $75.0 \%$ vs. $73.6 \%$ for ACR50, and $49.6 \%$ vs. $51.4 \%$ for ACR70, in patients who received CHS-0214 for 48 weeks $(n=224)$ vs. patients who received etanercept for 24 weeks and then switched to CHS-0214 for 24 weeks $(n=220)$, respectively. Thus, response rates were maintained both in patients who were switched at Week 24 from etanercept to $\mathrm{CHS}-0214$ and in patients who received CHS-0214 for 48 weeks.

Over the 52 -week study, adverse events (AE) were reported in $74.4 \%$ of patients who received CHS-0214 for 48 weeks and $76.6 \%$ who received etanercept for 24 weeks and were switched to CHS-0214 for 24 weeks. The majority of adverse events were mild or moderate in severity. No deaths were reported. Serious AEs were reported in $4.6 \%$ and $7.5 \%$ of patients, and serious AEs related to study drug per the investigator were reported in $0.9 \%$ and $1.9 \%$ of patients in the CHS-0214 and etanercept/CHS-0214 groups. Binding anti-drug antibodies (ADA) occurred in $1.3 \%$ and $4.7 \%$ of patients receiving CHS-0214 and etanercept during Part 1. In Part 2, treatment-emergent binding ADA occurred in $1.4 \%$ of patients receiving CHS- 0214 and $0.7 \%$ of patients who switched from etanercept to CHS-0214. Conclusions: This randomized, double-blind, active-control, global study demonstrated equivalence of CHS-0214 to etanercept based on the primary endpoint (ACR20 at Week 24) and maintenance of the efficacy response through Week 48 CHS-0214 was well tolerated and effective in patients with rheumatoid arthritis with no clinically meaningful differences to etanercept with regard to safety and immunogenicity. Over the 52-week study, no clinically meaningful differences in safety, immunogenicity, or efficacy were observed in patients who were switched from etanercept to CHS-0214 in comparison with those who only received CHS-0214.

Disclosure of Interest: J. O'Dell Consultant for: Coherus BioSciences, A. Kivitz: None declared, T. Takeuchi Consultant for: AbbVie, Asahi Kasei Pharma, Astellas, Astra Zeneca, BMS, Celtrion, Chugai, Daiichi-Sankyo, Eisai, Eli-Lilly Japan, Janssen, Mitsubishi Tanabe, Nippon Kayaku, Novartis, Pfizer, Sanofi-Aventis, Santen, Taisho Toyama, Takeda, Teijin Pharma, Y. Tanaka Consultant for: Abbvie, Astellas, BMS, Chugai, Daiichi-Sankyo, Eisai, GSK, Janssen, Mitsubishi-Tanabe, MSD, Novartis, Pfizer, Santen, Takeda, UCB, I. Louw: None declared, T. Tiabut Grant/research support from: Coherus BioSciences, S. Nakashima Employee of: Daiichi-Sankyo, J. Hodge Shareholder of: Coherus BioSciences, Employee of: Coherus BioSciences, H. Tang Shareholder of: Coherus BioSciences, Employee of: Coherus BioSciences, B. Finck Shareholder of: Coherus BioSciences, Employee of: Coherus BioSciences

DOI: 10.1136/annrheumdis-2017-eular.2480

\section{SAT0163 SYSTEMATIC SWITCH FROM INNOVATOR INFLIXIMAB TO BIOSIMILAR INFLIXIMAB IN INFLAMMATORY RHEUMATIC DISEASES IN DAILY CLINICAL PRACTICE: THE EXPERIENCE OF COCHIN HOSPITAL, PARIS, FRANCE}

J. Avouac $^{1}$, A. Molto ${ }^{1}$, V. Abitbol ${ }^{2}$, A. Salcion ${ }^{1}$, L. Gutermann ${ }^{3}$, O. Conort ${ }^{3}$ F. Chast $^{3}$, C. Le Jeunne ${ }^{4}$, C. Goulvestre ${ }^{3}$, S. Chaussade ${ }^{2}$, A. Kahan ${ }^{1}$, C. Roux ${ }^{1}$, Y. Allanore ${ }^{1}$, M. Dougados ${ }^{1}{ }^{1}{ }^{1}$ Rheumatology; ${ }^{2}$ Gastroenterology; ${ }^{3}$ Paris Descartes University, Cochin Hospital, Paris, France; ${ }^{4}$ Internal Medicine, Paris Descartes University, Cochin Hospital, Paris, France

Background: Biosimilars of originator biologic therapeutics are going to change medical practices. In October 2015, the medical community of Cochin Hospital decided to systematically propose the switch from innovator infliximab to biosimilar infliximab to all treated patients.

Objectives: To investigate efficacy and safety of switching treatment from innovator infliximab to biosimilar infliximab.

Methods: This is a usual care study conducted in patients aged $>18$ years who agreed to switch to biosimilar infliximab, and who received at least 3 infusions of innovator infliximab prior to the switch.

The primary outcome of the study was the retention rate of biosimilar infliximab at the time of the third infusion. Secondary outcomes included the factors associated with biosimilar discontinuation, the change between baseline and the last visit (July 2016) in DAS28-CRP (rheumatoid arthritis, RA), BASDAl/ASDAS (axial 
spondyloarthritis, axSPA) and infliximab trough levels, and the occurrence of adverse events.

Results: 260 patients fulfilled the inclusion criteria: 182 patients followed-up in Rheumatology (131 with axSPA, 31 with RA, and 20 with other inflammatory rheumatic diseases), 64 in Gastroenterology and 14 in Internal Medicine.

The retention rate at the time of the third biosimilar infusion was $82 \%(149 / 182$ patients), which was lower than the rate observed in patients with inflammatory bowel diseases or uveitis followed-up in Gastroenterology and Internal Medicine, respectively ( $71 / 78$ patients, $91 \%)$.

Between baseline and the last visit (mean follow-up: $34 \pm 4.5$ weeks), 48/182 (26\%) patients, including 36 patients with axSPA, discontinued biosimilar infliximab, mainly due to experienced inefficacy $(n=47)$. No clinical or biological factors were associated with biosimilar discontinuation.

One infusion reaction led to treatment discontinuation. No serious adverse events occurred. 43 patients restarted innovator infliximab, 2 patients switched to etanercept, 1 to abatacept and 2 maintained biological-free.

In RA patients, the mean DAS28-CRP remained stable from baseline to the last visit: $3.38 \pm 1.16$ to $3.08 \pm 1.08(\mathrm{p}=0.217)$. In axSpA patients, the mean BASDAl increased from $2.94 \pm 2.20$ to $3.18 \pm 2.21(p=0.046)$ and the mean ASDAS increased from $1.79 \pm 0.90$ to $1.99 \pm 1.08(\mathrm{p}=0.022)$. In RA and axSPA, mean CRP levels at baseline $(5.95 \pm 6.06$ and $5.98 \pm 11.14 \mathrm{mg} / \mathrm{l}$ respectively) and the last visit $(6.52 \pm 11.32$ and $5.03 \pm 8.26 \mathrm{mg} / \mathrm{l}$ respectively) were not statistically different $(p=0.289$ and $p=0.271$, respectively).

Mean infliximab trough levels were similar in patients with RA $(3.70 \pm 5.36$ vs. $3.21 \pm 4.35 \mu \mathrm{g} / \mathrm{ml}, \mathrm{p}=0.551)$ and AxSPA (5.88 \pm 5.82 vs. $5.70 \pm 5.42 \mu \mathrm{g} / \mathrm{ml}, \mathrm{p}=0.617$ ) during follow-up.

Conclusions: In the majority of patients, innovator infliximab can be switched to biosimilar infliximab without changes in efficacy and safety during 34 weeks follow-up. However, $26 \%$ of patients discontinued biosimilar infliximab, mainly those with AxSPA due to a subjective increase in BASDAI or ASDAS scores, possibly explained by suggestion or attribution effects rather than pharmacological differences.

Disclosure of Interest: None declared

DOI: 10.1136/annrheumdis-2017-eular.3791

\section{SAT0164 ASSOCIATION BETWEEN FLARE AND RADIOGRAPHIC} PROGRESSION IN PATIENTS WITH RHEUMATOID ARTHRITIS

\section{J.S. Smolen ${ }^{1}$, H. Jones ${ }^{2}$, E. Mahgoub ${ }^{2}$, R. Pedersen ${ }^{2}$, L. Marshall ${ }^{2} .{ }^{1}$ Medical} University of Vienna, Vienna, Austria; ${ }^{2}$ Pfizer, Collegeville, United States

Background: Biologic therapy has improved RA management, enabling some patients to achieve remission. Many clinicians decrease the biologic dose for patients in low disease activity (LDA) or remission. However, it is unclear which patients may flare and if flare contributes to radiographic progression.

Objectives: To assess whether patients who flared had a higher incidence of radiographic progression, and to compare patients with and without flares.

Methods: PRESERVE (ClinicalTrials.gov: NCT00565409) was a 2-period trial in patients with moderate RA despite MTX. Period 1 was open-label, single treatment induction with etanercept (ETN) $50 \mathrm{mg}+\mathrm{MTX}$ weekly (QW) for 36 wks. Patients in LDA or remission (disease activity score for 28 joints [DAS28] $\leq 3.2$ ) during wks 12 to 36 continued to Period 2, the randomized, double-blind phase to evaluate maintenance of LDA/remission. Patients were randomized to ETN $50 \mathrm{mg}+\mathrm{MTX} \mathrm{QW}, \mathrm{ETN} 25 \mathrm{mg}+\mathrm{MTX} \mathrm{QW}$, or placebo+MTX QW to wk 88. This post hoc analysis evaluated flare and radiographic progression at wk 88 . Flare was defined 2 ways: 1) loss of LDA with/without DAS28 change of 0.6; and 2) relapse (DAS28 $>5.1$ or DAS28 $>3.2$ at $\geq 2$ time points). Radiographic progression was evaluated according to 4 levels of stringency: 1) minimally clinically important difference (modified total Sharp score [mTSS] change $\geq 5$ ); 2) smallest detectable difference (mTSS change $\geq 2.3$ ); 3 ) mTSS change $\geq 0.5$; and 4) mTSS change $>0$. Baseline $(\mathrm{BL})$ characteristics were compared for patients with vs without flare, defined as loss of LDA and DAS28 change of 0.6. Analysis of covariance and chi-square test compared continuous and categorical outcomes, respectively.

Results: Age, race, BMI, and disease duration did not differ significantly for flare vs non-flare, total $\mathrm{N}=531$. BL DAS28 was higher for flare vs non-flare: mean (SD)

Table. Radiographic progression at week 88

\begin{tabular}{lccc}
\hline Outcome & Flare Patients & Non-flare Patients & P-value $^{*}$ \\
\hline $\begin{array}{l}\text { Flare defined as loss of LDA and DAS28 change of 0.6 } \\
\text { mTSS }>0\end{array}$ & & \\
mTSS $\geq 0.5$ & $43 / 271(15.9)$ & $31 / 260(11.9)$ & 0.2109 \\
mTSS $\geq 2.3$ & $38 / 271(14.0)$ & $24 / 260(9.2)$ & 0.1045 \\
mTSS $\geq 5.0$ & $20 / 271(7.4)$ & $10 / 260(3.8)$ & 0.0914 \\
Flare defined as loss of LDA & $9 / 271(3.3)$ & $2 / 260(0.8)$ & 0.0633 \\
mTSS $>0$ & $44 / 280(15.7)$ & $30 / 251(12.0)$ & \\
mTSS $\geq 0.5$ & $39 / 280(13.9)$ & $23 / 251(9.2)$ & 0.2586 \\
mTSS $\geq 2.3$ & $20 / 280(7.1)$ & $10 / 251(4.0)$ & 0.1043 \\
mTSS $\geq 5.0$ & $9 / 280(3.2)$ & $2 / 251(0.8)$ & 0.1338 \\
Flare defined as relapse & & & 0.0670 \\
mTSS $>0$ & $35 / 181(19.3)$ & $39 / 350(11.1)$ & \\
mTSS $\geq 0.5$ & $31 / 181(17.1)$ & $31 / 350(8.9)$ & 0.0119 \\
mTSS $\geq 2.3$ & $19 / 181(10.5)$ & $11 / 350(3.1)$ & 0.0065 \\
mTSS $\geq 5.0$ & $9 / 181(5.0)$ & $2 / 350(0.6)$ & 0.0011 \\
\hline
\end{tabular}

${ }^{*}$ Fisher's exact test. Overall treatment group. Values are $\mathrm{n} / \mathrm{N}(\%)$.
$4.37(0.45)$ vs $4.27(0.45), p=0.046$. Other $\mathrm{BL}$ disease characteristics were similar between groups. With flare defined as relapse, significantly more flare than nonflare patients showed all 4 degrees of radiographic progression (table). With flare defined as LDA loss with/without DAS28 change of 0.6 , radiographic progression did not differ significantly between groups, but numerically more patients with flare progressed. This was the trend for all treatments; the numbers were too small to analyze. Numerically more placebo patients progressed, regardless of flare status or progression category (data not shown).

Conclusions: Using relapse as a rigorous definition of flare, radiographic progression occurs in significantly more flare than non-flare patients, demonstrating that it is a consequence of flare following biologic withdrawal.

Disclosure of Interest: J. Smolen Grant/research support from: Abbvie, Janssen, Lilly, MSD, Pfizer, Roche, Consultant for: Abbvie, Amgen, Astra-Zeneca, Astro, Celgene, Celtrion, Glaxo, ILTOO, Janssen, Lilly, Medimmune, MSD, NovartisSandoz, Pfizer, Roche, Samsung, Sanofi, UCB, Speakers bureau: Abbvie, Amgen, Astra-Zeneca, Astro, Celgene, Celtrion, Glaxo, ILTOO, Janssen, Lilly, Medimmune, MSD, Novartis-Sandoz, Pfizer, Roche, Samsung, Sanofi, UCB, H. Jones Shareholder of: Pfizer, Employee of: Pfizer, E. Mahgoub Shareholder of: Pfizer, Employee of: Pfizer, R. Pedersen Shareholder of: Pfizer, Employee of: Pfizer, L. Marshall Shareholder of: Pfizer, Employee of: Pfizer DOI: 10.1136/annrheumdis-2017-eular.1854

\section{SAT0165 REAL-WORLD UTILIZATION OF CONCOMITANT MEDICATIONS IN PATIENTS INITIATING ETANERCEPT: A RETROSPECTIVE COHORT STUDY OF CANADIAN CLAIMS-LEVEL DATA}

M. Khraishi $^{1}$, Y. Zhang ${ }^{2}$, J. Ivanovic ${ }^{2}$, B. Millson ${ }^{2}$, M.-J. Brabant ${ }^{2}$, E. Singh ${ }^{3}$, J. Woolcott ${ }^{4}$, H. Jones ${ }^{3} .{ }^{1}$ Faculty of Medicine, Memorial University of Newfoundland, St. Johns; ${ }^{2}$ Health Access \& Outcomes, QuintilesIMS, Kanata, Canada; ${ }^{3}$ Inflammation and Immunology, Global Medical Affairs, Pfizer Inc., Collegeville, United States; ${ }^{4}$ Health Economics and Outcomes Research, Pfizer Inc., Kirkland, Canada

Background: Methotrexate (MTX) and prednisone (pred) are immune suppressants frequently used to treat immune-mediated inflammatory diseases (IMIDs). Etanercept is a soluble TNF receptor (humanized protein) indicated for the treatment of IMIDs, including rheumatoid arthritis (RA), psoriatic arthritis (PsA), psoriasis (PsO), and ankylosing spondylitis (AS). Limited information exists on how MTX or pred use changes in patients who initiate etanercept in real-world settings.

Objectives: To evaluate whether initiation of etanercept impacts use of co-therapy with MTX or pred in Canadian patients with IMIDs.

Methods: A retrospective cohort study was conducted using claims-level data from QuintilesIMS Private Drug Plan database, Ontario Public Drug Plan database, and Quebec Public Drug Plan database. Bio-naïve patients initiating etanercept between $07 / 2013$ and 06/2015, were identified and their claims made for MTX or pred were analyzed. Patients' utilization of MTX or pred was calculated as average weekly dose in $\mathrm{mg}$, and then compared in the 6-months pre versus 12-months post initiation of etanercept using a paired t-test. Differences in the presence of concomitant medications pre and post-etanercept were also examined using a paired t-test.

Results: The study captured 3,745 etanercept patients $(61 \%$ female, $77 \%$ aged between 18 and 65, 84\% rheumatic diseases, and 15\% PsO) across Canada in the selection period. Of selected patients, 33\% used MTX $(n=1,244)$ and $14 \%$ $(n=523)$ used pred pre and post initiation of etanercept. In concomitant MTX patients, the average weekly dose dispensed was $25.2 \mathrm{mg}$ in the 6 months prior to initiation of etanercept, and $25.0 \mathrm{mg}$ in the 12 months following the first claim of etanercept ( $p=0.7493)$. In concomitant prednisone patients, the average weekly dose dispensed reduced from $123 \mathrm{mg}$ pre-etanercept to $108 \mathrm{mg}$ post-etanercept initiation $(p=0.2316) .19 \%$ of patients stopped MTX $(n=287)$ use post-etanercept initiation, compared to $36 \%$ who stopped pred use $(n=289)$.

Conclusions: In this real-world setting, approximately $1 / 5$ of patients stopped or reduced co-therapy of MTX; and 1/3 of patients stopped or reduced co-therapy of pred following initiation of etanercept; however, those patients who remained on co-therapy showed non-significant changes in their average consumption. Further research is needed to understand the impact on overall patient outcomes and safety.

Disclosure of Interest: M. Khraishi Consultant for: Pfizer Canada and Amgen Canada, Y. Zhang: None declared, J. Ivanovic: None declared, B. Millson: None declared, M.-J. Brabant: None declared, E. Singh: None declared, J. Woolcott: None declared, $\mathrm{H}$. Jones: None declared

DOI: 10.1136/annrheumdis-2017-eular.6947

\section{SAT0166 MARKERS OF RESPONSE TO INFLIXIMAB IN RHEUMATOID ARTHRITIS - THE PLACE OF ANTINUCLEAR ANTIBODY AND NUCLEASE SERUM ACTIVITY}

M. Volkava ${ }^{1}$, A. Kundzer ${ }^{1}$, I. Generalov ${ }^{2}$, D. Petrovich ${ }^{1} .{ }^{1}$ Cardiology and Rheumatology, BeIMAPGE, Minsk; ${ }^{2}$ Clinical Microbiology, VSMU, Vitebsk, Belarus

Background: It is important to study new potential markers of response to treatment in rheumatoid arthritis (RA), because up to $40 \%$ patients don't achieve 